\title{
Familial Association of Gilberts and Beta Thalassemia Trait
}

Jishu Deb Nath

Department of Medicine

Chattagram Maa-O-Shishu Hospital Medical College Chittagong, Bangladesh.
*Correspondence to:

\section{Dr Jishu Deb Nath}

Assistant Professor

Department of Medicine

Chattagram Maa-Shishu-O- General Hospital

Chittagong, Bangladesh

Mobile: +88-01716405056

E mail:jishudebnath2007@gmail.com

\section{Abstract}

A 21 yrs old male from Jatrabari, Dhaka became unfit to travel to Gulf, as his serum bilirubin was found $5.7 \mathrm{mg} / \mathrm{dl}$. He was diagnosed to have Thalassemia trait along with Gilbert's syndrome. His elder brother has also got similar diseases from age 14 . Here both associations of these diseases with positive family history are highlighted.

Key words: Gilbert syndrome; thalassemia trait; hyperbilirubinemia; rifampicin test; autosomal recessive disorder; uridine diphosphate glucuronyltransferase.

\section{INTRODUCTION}

Gilbert syndrome is the most common inherited disorder of bilirubin metabolism. This disease may be precipitated by dehydration, fasting, or stress, an intercurrent febrile disease or vigorous exercise. Rarely, the disorder occurs with some primary haematolgoical disorder such as -thalassemia minor (thalassemia trait), glucose-6phosphate dehydrogenase (G-6 PD) deficiency and hereditary spherocytosis ${ }^{1}$. Here, we describe one such patient having GS and thalassemia trait with familial association.

\section{CASE REPORT}

A 21 yrs old student was willing to migrate to Gulf countries, but his medical report became unfit as his serum bilirubin was found $5.7 \mathrm{mg} / \mathrm{dl}$. Apart from few days of nausea, patient had no symptoms suggestive of liver diseases. He reported taking no over-the-counter medications. His review of systems was unremarkable. Specifically, he reported no abdominal discomfort; nausea; vomiting; or changes in bowel habits or skin, urine, or stool color.

He reported no known drug allergies. He was a lifetime nonsmoker, had no significant travel and exposure history. But his elder brother, 25 yrs was diagnosed as thallasemia minor and history of fluctuating jaundice since age 14. His Physical examnation showed a well-nourished body with normal growth and development. Liver span was normal, but spleen was just palpable. There were no signs of ecchymosis or bruising any where in the whole body.

Laboratory testing showed normal serum chemistry values, renal function, and glucose levels. On examination of peripheral blood smear red blood cells (RBC's) were markedly microcytic and hypochromic. Few target cells were also seen. Mean corpuscular volume (MCV) was $68 \mathrm{fl}$. On $\mathrm{Hb}$ electrophoresis $\mathrm{HbA} 2$ was $4.7 \%$. $\mathrm{HbF}$ was normal. Although his aspartate aminotransferase (AST) and alanine aminotransferase (ALT) levels had been mildly elevated. His total bilirubin and direct bilirubin values were elevated at $3.8 \mathrm{mg} / \mathrm{dL}$ and $0.8 \mathrm{mg} / \mathrm{dL}$, respectively. Gilbert syndrome was suggested, and after 2 day , rifampin test was performed. Total serum unconjugated bilirubin concentrations were measured at baseline and 6 and 24 hours after the administration of oral $600 \mathrm{mg}$ rifampin, showing values of 1.9, 2.9 and $4.4 \mathrm{mg} / \mathrm{dl}$, respectively. Direct and indirect Coombs tests were negative. Abdominal sonogram disclosed splenomegaly $(13.3 \mathrm{~cm})$. 


\section{DISCUSSION}

This disorder, the most common inherited cause of unconjugated hyperbilirubinemia, was first described by Augustine Gilbert and Pierre Lereboullet in $1901^{2}$. Later, Arias ${ }^{3}$ described a disorder in which eight patients with chronic nonhemolytic jaundice had glucuronyltransferase deficiency. The patient was diagnosed to have thalassemia trait based on profound microcytosis, hypochromia with target cells, mild anemia, raised $\mathrm{HbA} 2$ and unconjugated hyperbilirubinemia.GS was diagnosed on basis of unconjugated hyperbilirubinemia, normal values of liver function tests and normal heptic histology. Diagnosis of GS was further confirmed on subjecting the patient to rifampicin test ${ }^{4}$.

Gilbert syndrome is inherited as an autosomal dominant trait and that patients are heterozygous for a single abnormal gene ${ }^{5}$. Plasma bilirubin level in normal subjects varies with gender; the postpubertal males have higher levels than females ${ }^{6}$ and this may be due to the effect of female hormones on UDPglucoronosytruferase $\mathrm{e}^{7,8}$. However, the condition is more frequent in males, even allowing for this natural difference, as the reported male to female ratio is $2.7: 1.9$. The reported prevalence of Gilbert syndrome

varies from $3 \%$ to $12 \%$ in various ethnic groups $5,8-10$ Because positive family history was reported in less than $4 \%$ of patients, $27 \%$ to $55 \%$ of siblings and $16 \%$ to $26 \%$ of parents, ${ }^{9,10}$ the familial history cannot be considered an essential part of the diagnostic workup of Gilbert disease.
The genetic basis of the disease was elucidated in $1995^{11}$. Decreased hepatic bilirubin uridine diphosphate glucuronsyltransferase factor, though transport abnormality in hepatocytes and occult hemolysis may also contribute.

Recent advances in genetics research have demonstrated that GS is associated with a homozygous polymorphism-A(TA)7 TAA instead of A(TA)6 TAA in the TATA box of the promoter region of the UGT1A1 gene ${ }^{12}$, the gene that encodes bilirubinUGT). The presence of the longer TATAA element in patients with GS results in the reduced expression of a reporter gene. There are two genetic mutations possible in $\mathrm{GS}^{13}$. The first clinical phenotype can be described as the polymorphism present in the TATA box promoter region of the UGT1A1 gene, as was the case with our patient. The other variant is caused by missense mutations in the coding region of the UGT1A1.

It is highlighted that the patients with both GS and thalassemia trait have higher bilirubin concentrations because the (TA) $7 /(\mathrm{TA}) 7 \mathrm{GS}$ genotype is one of the factors accounting for the hyperbilirubinemia observed in thalassemia major, intermedia, and heterozygous individuals ${ }^{14}$.

In conclusion, Gilbert's syndrome should be suspected if the patient has a mild hyperbilirubinemia with a high fraction of unconjugated bilirubin, normal

liver function, and no overt signs of hemolysis. But in presence of hemolysis, alternative diagnosis or another association should be sought.

\section{DISCLOSURE}

The author declared no competing interest.

\section{REFERENCES}

1. Avasthi R, Agarwal S, Ram BK. Gilbert's syndrome. J Indian Med Association 1995;93:403

2. Gilbert A, Lereboullet P. La cholemie simple familiale. Semaine Med 1901;21:241-3.

3. Arias IM. Chronic unconjugated hyperbilirubinemia without overt signs of hemolysis in adolescents and adults. J Clin Invest 1962;41:2233-45.

4. Erdil A, Kadayifci A, Ates Y, Bergis S, Uygun A. Rifampicin test in the diagnosis of Gilbert's syndrome. Int J Clinic Practice 2001;55:81-3

5. Watson KJR, Gollan JL. Gilbert syndrome: Bailliere's Clinical Gastroenterology, International Practice and Research. April 1989;337-56.

6. Muraca M, Blanckaert N. Liquid chromatographic assay and identification of mono and diester conjugates of bilirubin in normal serum. Clin Chem 1983;29:1767-71.

7. Muraca M, Fevery J. Influence of sex and sex steroids on bilirubin uridine diphosphate-glucoronosyl transferase activity of rat liver. Gastroenterol 1984;87:308-13.

8. Foulk WT, Butt HR, Owen CA, et al. Constitutional hepatic dysfunction (Gilbert syndrome): its natural history and related syndrome. Medicine 1959;38:25-46.

9. Baroody WG, Shugart RT. Familial nonhemolytic icterus. Am J Med 1956;20:314-6.

10. Watson KJR, Gollan JL. Gilbert syndrome: Bailliere's Clinical Gastroenterology, International Practice and Research. April 1989;337-56.

11. Bosma PJ, Chowdhury JR, Bakker C, et al. The genetic basis of the reduced expression of bilirubin UDPGlucuronosyltransferase 1 in Gilbert's syndrome. N Engl J Med 1995;333:1171-5.

12. Kamisako T. What is Gilbert's syndrome? Lesson from genetic polymorphisms of UGT1A1 in Gilbert's syndrome from Asia. J Gastroenterol Hepatol. 2004;19(9):1023-1028.

13. Hallal H, Egea JM, Mas P, García MD, Pérez- Cuadrado E, Carballo F. A shortened, 2-hour rifampin test: A useful tool in Gilbert's syndrome. Gastroenterol Hepatol. 2006;29(2):63-65.

14. Ellis E, Wagner M, Lammert F, et al. Successful treatment of severe unconjugated hyperbilirubinemia via induction of UGT1A1 by rifampicin. J Hepatol. 2006;44(1):243-244. 